\title{
Exploring the Teacher Behaviors that Influence High School Student's Class Participation in the UAE
}

\author{
Olatunji Jacob Ajayi and Alexandria A. Proff \\ Department of Humanities and Social Sciences, American University of Ras Al Khaimah, United Arab Emirates \\ *Correspondence: Alexandria A. Proff, alexandria.proff@aurak.ac.ae
}

\begin{abstract}
Teachers are entrusted with the responsibility of ensuring teaching and learning takes place in the classroom; several challenges exist, however, that influence the degree to which teachers may find success in teaching and learning. This phenomenological case-study explored the perceptions of six high school science teachers concerning the teacher behaviors that influence high school student's classroom participation within the Emirati private educational system. Semistructured interviews were conducted with purposefully sampled participants; data was analyzed via content analysis, which employed utilized multiple stages of coding: open, axial, and thematic. The findings of this research resulted in three main themes: (1) Teachers who model positive behaviors increase student's classroom participation; (2) An empathetic understanding of teachers-needs would lead to more effective teacher support; and (3) Field experience coupled with effective support facilitates positive perceptions of student-teacher relationship. The findings of this research indicate a strong need for active teachercoaching and teacher-mentoring, rather than passive, primarily rote, teacher training programs that are common in schools as the primary form of professional development. It also demonstrates the need for school leaders and teachers to foster meaningful, positive relationships with students so as to improve performance. This research paper further contributes to closing the literature gap on Student-Teacher (S-T) relationships by providing new knowledge concerning the lived-experiences of high school science teachers in fostering meaningful S-T relationships.
\end{abstract}

Keywords: Classroom participation, S-T relationship, Teacher behaviors, Teacher support

\section{ARTICLE INFORMATION}

Author(s): Olatunji Jacob Ajayi and Alexandria A. Proff

Received: 23 Apr, 2021; Accepted: 21 June, 2021; Published: 30 June, 2021 e-ISSN: 2347-4696;

Paper Id: BMN-IJBMR-2021-37;

Citation: $10.37391 /$ IJBMR.090215

Webpage-link:

https://ijbmr.forexjournal.co.in/archive/volume-9/ijbmr-090215.html

\section{INTRODUCTION}

The nobility of teaching is profound and immeasurable as education lays the foundation of human cognition and development. Teachers are generally known for imparting knowledge, but aside that, teachers are encompassed with greater responsibility to serve as agents of change and to proffer solutions to problems encountered in teaching practice. Due to the resilience-building power of teachers, they are able to influence their colleagues, parents, and administrators; their primary influence, however, is on their students but unfortunately, there are many barriers to that, hence the need for research.

\subsection{S-T Relationship}

Crow, et al. [1], stated that "strong and positive studentteacher relationships (S-T relationships) influence students and their success". According to them, building an S-T relationship must be purposeful with continual effort primarily on the part of the teacher. This will, in turn, enhance learning and make it flourish in the classroom whereas doing otherwise has proved unproductive to students learning. Other studies suggest that teachers should show more leadership and understanding behaviors and less uncertain behaviors in class if they want to improve academic achievement [2-4]. However, a qualitative approach is needed to help explain how patterns of behavior exhibited by teachers can change student's perception, thereby enhancing their achievement in the classroom. Students are cognizant when teachers genuinely care about their well-being and their education. It is evidenced in the rigor of the instruction, the way they are spoken to, and by understanding the students' circumstances. When students perceive teachers as valuing their learning, they tend to work harder and prioritize their learning $[5,6]$.

\subsection{Teaching Science}

Science is curiosity in thoughtful action about the world and how it behaves. It is an art that involves making observations, asking questions, forming hypothesis, carrying out experiments to test the hypothesis, analyzing the results from experiments and presenting the impactful result to the world. The world of science is growing at an ever-increasing rate, but the number of people going into science is not keeping the pace. Some students who were once interested in science decided to leave the pipeline in high school due to the fact that they claimed science was hard, and there weren't enough science advocates at school [7-9]. This might be traced to how science is been taught in schools, because only a fairly small fraction of high school students goes to college with an interest in becoming scientist [10]. A study carried out by Guedenon, et al. [11] showed that science classroom practices can be enabled by using audio-visual materials as against the popular rote text-image method existent in the study of Pylons High school, Cotonou. Other problems related to the pedagogical style included issues of communication and relational atmosphere between teachers and learners. 


\subsection{Teacher Behavior}

Teacher behavior could either be positive or negative, but in the context of this problem of practice, it is the positive behaviors that keep students engaged in a classroom setting. Teacher's negative attitude includes discrediting, revenge, strict discipline, lack of interest, favoritism, annoyance, unkindness, narrow-mindedness, misunderstanding and unpredictability [12-14]. A recent study by Ali, et al. [15] further established that teachers' positive behavior has positive effects on students' career building and personality development, whereas negative behavior has a negative impact on students' performance and character building. Students in the above study confirm that the effects of teacher's favoritism make them work hard for favoritism instead of focusing on their studies, hence affecting their academic achievement.

Sutherland and Morgan [16] outlined the transactional theory of social interactions and discussed the importance of understanding reciprocal relationships between teachers and students' behavior. According to Sutherland \& Morgan [16], "Transaction occur when an individual is influenced by another individual's behavior to do something that they may not otherwise do". This implies that behavior, perceived as either good or bad, could cause one to reciprocate in ways that may or may not be consistent with another individual's values. They went further to explain that these reciprocal interactions can result in abnormalities in students' behavior and less academic achievement. A better understanding, however, of reciprocal interactions will strengthen the quality of instructions for students.

\subsection{Self-Efficacy}

Teaching has become a circular and continuously interactive process with causes and effect. Just like Newton's third law of motion which states that for every action, there is an equal and opposite reaction, there are consequences for the behavior teachers exhibit in the classroom. Bandura [17] explains this, by defining outcome expectancy as a person's estimate that a given behavior will lead to certain outcomes, and efficacy expectation as the conviction that one can successfully execute the behavior required to produce the outcomes. We can imply that a course of action will produce certain outcomes and the degree of people's conviction in their own effectiveness is likely to affect whether they will even initiate a coping behavior. Bandura further argued that teachers' self-efficacy beliefs affect not only their specific instructional activities, but also their general orientation toward the educational process [18-20]. It is apparent from different studies that teachers' behavior results from many factors [17, 21], nevertheless teachers should be aware of their likely reactions, learn to make sense and moderate the consequences of their feelings and manage the behaviors that is of great benefit to students in other to influence them positively in class participation.

\subsection{Professional Development}

Harris, et al. [22] carried out a study to show the effect of teacher behavior on pupil academic performance. The result of their study showed a huge disparity between the teaching behavior of ten untrained and ten trained teachers, while teaching a brief lesson to about eighty students. It was also revealed that some specific teacher behaviors such as nonverbal warmth and task orientation enhanced student performance. Non-verbal warmth "suggest that teachers made special effort to deliver critical verbal feedback in a warm and supportive nonverbal manner" [22]. According to the above study, trained teachers promoted significantly better academic self-concepts in their students and reports from the students confirmed that they enjoyed the session more when taught by a professional teacher. In line with the above study, teachers who care less about how their behavior affect their students could be termed untrained, hence needing a professional development [23-25].

\subsection{Education in the UAE}

The United Arab Emirates (UAE) has an ongoing effort to develop an effective education system that prepares its students and educational institutions to become catalysts for innovative research and development, and to allow the nation to grow competitively within the global economy. The UAE's first president, Sheikh Zayed Bin Salem Al Nahyan asserted that "greatest use that can be made of wealth is to invest it in creating generations of educated and trained people" [26]. In addition to that, the UAE has mandated all teachers in public and private schools to sit for and pass a licensing examination in pedagogy and specialization subject. This is an effort of the government to enhance and standardize its education system by 2021 [27, 28]. In conformity with the UAE agenda, this paper hopes to build on the works of other researchers on the above problem of practice, limit the scope of the work to high school science teachers in the UAE (Sharjah), and to critically explore specific behaviors that could influence student's participation especially in the classroom.

\section{METHODOLOGY}

\subsection{Research Questions}

This study aims to explore the teacher behaviors that influence student participation in a classroom setting. Upon a thorough review of relevant literature, it is evident that student's perception of a teacher has great influence on their responsiveness in the classroom [1, 6, 15]. Essentially, the research questions that this study intends to address are given below:

1. How do high school science teachers with positive S-T relationship influence student's classroom participation? (Teacher behaviors)

2. What support exists to help high school science teachers foster student participation in their classroom? (Teacher support)

3. How do high school science teachers' perception of a positive S-T relationship evolve overtime when provided with specific support? (Evolving perception)

By addressing the questions above, this study hopes to gain a deeper insight into the various teacher behaviors that motivate high school students, and the specific supports needed for 
teachers to foster greater responsiveness to instruction and improve classroom participation.

\subsection{Research Approach and Design}

This research employed a qualitative approach because it aimed at getting closer to the lived experiences of teachers, and their perspectives on S-T relationship. This was done via detailed interviewing and classroom observation [29]. This research method enabled the researcher to take advantage of issues that arose during data collection as well as focusing on pre-determined discussions [30]. Considering the nature of the research, a phenomenology approach was adopted to garner insight concerning the behaviors of teachers that influence student participation in the classroom. Phenomenology is an approach to qualitative research that focuses on the commonality of lived experiences within a particular group [31]. This qualitative approach enables researchers to sufficiently describe the observed phenomenon.

\subsection{Sampling and Criteria}

The number of science teachers who partook in this study were six, and they work in a school in Sharjah, UAE. The sampling of the study was opportunistic according to the criteria below; hence, the study will not generalize the findings to the wider population $[32,33]$.

Criterion One, Full-Time Employment: Participants in this study are full- time high school science teachers. As this study seeks to understand the teacher behaviors that influence high school student's classroom participation, full-time teachers are best suited to address these facets of the study.

Criterion Two, Language Teaching: Participants in this study were either male or female teachers who teach science using English as the language of instruction. In delimitating the scope of this phenomenological research, the researcher chose to narrow the focus of teaching science to English language fluency.

Criterion Three, S-T relationship: Participants in this study were Science teachers who have a strong and positive studentteacher relationship with their students already. This is evident in the high-quality student's participation experienced in their classroom. This is important, as this study seeks to understand the behaviors modelled by these teachers which motivated students to participate more in their classes.

Criterion Four, No Evaluative Role: The researcher did not hold any supervisory or evaluative role over the participants to ensure they are free of coercion. This is important as the study seeks to glean insight into the lived experiences of the participants [34].

The total population eligible for participation in this study was $8(n=8)$. While the researcher anticipated conducting between six to eight semi-structured interviews, data collection continued until a point of saturation was attained and the research questions been fully answered. The total number of semi-structured interviews was six.

\subsection{Data Collection and Analysis}

With the purpose of collecting data and getting an idea of teachers' behaviors that science teachers use in the classroom, semi-structured interviews with teachers was carried out. This technique helps the researcher to gather in-depth data about the interviewees' ideas and viewpoints as related to the study. $[32,35]$. The interviews were between 40 to 60 minutes in length and the researcher recorded all the interviews, after obtaining the written consent of the participants. Participants in this study were given ample time to reflect on some of their responses, to consider the effectiveness and limitations of expressed behaviors to students in the course of their career as a teacher. This is important so as to seek their perspectives about positive $\mathrm{S}-\mathrm{T}$ relationships in general.

Data analysis started as soon as the first interview was conducted. The recorded interview was converted to a typed text in the form of transcript. The three research questions were given anchor codes 'teacher behavior', 'teacher support' and 'evolving perceptions' respectively. The transcripts were read many times, to determine the empirical indicator (potentially relevant information) which is linked to the anchor codes, and analyzed to form initial codes [30, 36, 37]. Based on the nature of the research and the research question, an interpretative coding strategy was used to develop open codes that best represents the empirical indicator. Coding is the transparent process of reducing data to meaningful concepts which adequately represent the data and address the research questions [36]. Corroborating evidence from observations during the interviews were used to understand the codes better. Similar codes were grouped in a compilation sheet for easy categorization which emerged to form axial codes [36]. Notes was taken in the initial memo to illustrate the development of the axial codes and the inter-relationships between them. Finally, the axial codes of similar attribute were organized into final themes, and a narrative was written to tell the story of the data

\section{FINDINGS}

The presentation of the findings is organized according to the themes that emerged from the content analysis employed in this qualitative study. The implications of these data will be analyzed in the discussion section. A summary of participant background information is provided in Table One. Each participant was assigned a pseudonym to safeguard their anonymity and maintain confidentiality. The findings below use these pseudonyms in reference to the participants.

\begin{tabular}{|l|l|l|}
\hline \multicolumn{1}{|c|}{ Pseudonym } & $\begin{array}{c}\text { Years of teaching } \\
\text { experience }\end{array}$ & Education Level \\
\hline Mariam & 7 years & Bachelor's Degree \\
\hline Rand & 7 years & Bachelor's Degree \\
\hline Shafqat & 11 years & Bachelor's Degree \\
\hline Wessam & 5 years & Bachelor's Degree \\
\hline Hamad & 10 years & Bachelor's Degree \\
\hline Salem & 8 years & Bachelor's Degree \\
\hline
\end{tabular}

Table 1: Participant's background information. 


\subsection{Theme One: Teachers Who Model Positive Behaviors Increase Student Classroom Participation}

To begin with, all participants of this study have previously established strong and purposeful student-teacher (S-T) relationship in their career as teachers, which enabled a positive classroom climate for high quality student's classroom participation. This theme emerged from participants' responses during the interview, where general questions were asked about how they influence student's classroom participation. The behaviors in no particular order are assuming parental role; giving student's responsibility; being creative; and sense of humor.

Mariam explained how assuming a parental role enhances student's classroom participation, "So, they find me in another situation, I am a mother here not a teacher. Not the one that always telling them to be quiet, so some gets in love with me, some can accept me, some didn't and that [is] normal because we are human beings." Assuming a parental role describes seeing your students as though they were your children; that is a high level of attentiveness, a concerted effort toward their growth and development, and providing students with high level of emotional and psychosocial support. According to Rand, one assumes a parental role by using words of affirmation when communicating with students, "How are you or a good morning would be perfect, that as a teacher you know them by name, this is so personal and they start to care back, they start to care about you and of course your subject". In addition, Rand asserted that another way teachers can assume a parental role is to serve as role models, "One more right behavior and I learned that over time is be a role model in a classroom. Even if you are going to ask a question from a student, hello, say his name and can you answer this question. This will set a class routine; it takes time I know."

Another positive behavior modelled by participants of this study refers to providing students with opportunities to exercise responsibility. Hamad stated that one of the reasons why students do not participate in science class is because they are not given responsibilities to express them themselves, "... lecturing, when the teacher will start from the first minute to the last minute and even doesn't give chance to students to express themselves." Shafqat agreed with this sentiment by suggesting that "all the instructions were on paper so that they can read and can do everything by their own." Providing students with opportunities to exercise responsibility encompasses the ways in which teachers facilitate learners to engage more fully in the learning process.

In addition, five out of six participants shared the idea that teacher's creativity can also improve student participation. Wessam stated that "for the improvement we can say that some teachers only focus on theoretical work, and this is the mistake that the science teachers did here. They should, for example, do some visual concepts something that they can create; something that they can imagine, this is the important thing." Being creative describes the teacher's ability to generate original ideas to create something that will promote student participation in the classroom. This may include new activities that engage and/or intrigue the students. Salem inferred that connecting concepts to real life situations is part of the creativity of a teacher, "So they give you a lot of questions they feel like okay they just connected to the life, so they know, and this is the best way that you just connect every lesson with your life or their life, the situations that happen to them, situation that you mention in class."

Finally, one more perception across all participants is that that humor is a key to getting students engaged. Mariam stated that, "he has to make some fun to break the ice even if that's not the first time he is teaching." This includes recognizing when students begin to lose focus; Mariam suggested that she stops instruction, interjects a bit of humor with a joke in order to re-engage students in the learning process. She also stressed, however, that expressing your sense of humor to students should be done with caution by setting flexible boundaries, "yes because high school is a critical age, when they think you are too friendly, they think they can climb you"

\subsection{Theme Two: An Empathetic Understanding of Teacher-Needs Would Lead to More Effective} Teacher Support

In each interview, the researcher asked the participants what kind of support exists to enhance student's classroom participation, and whether they are getting enough support from the school administration. The kind of support common across participant responses shows that teachers have access to technology, access to laboratory equipment and they sometimes receive resources to facilitate science activities.

Mariam confirmed by saying "yes, they are still working in labs, so they allow us to enter the labs, they try to get more things for us. So yeah, they are trying, the event; I have done many events in this school, so they are facilitating the events." To support the above point, the Hamad stated that "for example, I'm using the schools' laptop so this will be the resource I can use that give me a support. Sometimes they are giving us the pen or marker these stationary maybe even if they are, like, cheap but at the time it can facilitate the work". While this participant reported having access to some resources, a majority of participants, four out of six, suggested otherwise, attributing this lack of resources to school leaders who lack an empathetic understanding of what they really need. Mariam stated that "I think our management, now, is trying to do their best but still I see there is a big gap between us and them and that's why the students are always feeling the gap. Students are not stupid. They don't have empty heads". Shafqat echoed a similar sentiment, suggesting that "Nobody is encouraging, nobody is saying oh good job, that you are doing an excellent job."

Each participant in this sample attested that the passive, rote professional development trainings, are not effectively meeting their needs. Shafqat asserted that "It's just like they bring power point slides and read that from United States or somewhere, so you know this is applicable there, because the culture, is different, so we have to find another way, another 
better way. We have to have support from admin actually, yes this is the problem". Rand suggested a better way to support teachers by recommending coaching mechanism for teachers, "You cannot teach some Indian guy, some Arab guy and some European guy to be the same guy. This will never happen, until you give them coaching, the situation of what happens, so coaching actually supports this". Rand is of the opinion that training is not sufficient because it is only about transferring knowledge whereas coaching is about enhancing knowledge in a more practical and individualized way. Obviously, coaching is a way to apply learning in an informed way, therefore Rand believes that teachers will get more help via a blend of teacher training and coaching.

Another key point highlighted by participants is a perception that school administrators lack empathy and trust with teachers. A supermajority of participants, five out of six, in the study stated that school leaders do not trust them, and they report feeling unprotected against verbal harassment from parents. Shafqat stated that "but the problem is [the] parents; [when it comes to parent complaints] we didn't have any support... some teachers get terminated because of the parents." Salem further stated that "some kids they know they can fire teacher because he takes salary from my side." Teachers in this sample articulated that the school administrators do not help protect teachers from verbal abuse from unhappy students and parents. This lack of empathy, coupled with an absence of enforcing meaningful procedures for grade appeals, from school administrators may promote a mindset among students and parents that have the power to influence terminating a teacher just because they pay tuition. Hamad asserted that "the management should give some, like, limitations for the parents. The teacher, he is the perfect one to decide what he should explain [and] what [the] teacher does not explain." In short, a majority of teachers in this study do not feel that school administrators understand their utmost needs, and, therefore, are not able to provide effective support.

Improving the support teachers receive in schools would likely produce more inclusive workspaces that promote involvement, trust, and motivation between school administrators and teachers. This lack of support in terms of access to resources, as well as limited empathy allude to a stressful atmosphere in schools that teachers suggest hindering the development of meaningful student-teacher relationships and student participation.

\subsection{Theme Three: Field Experience, Coupled with Effective Support, Facilitates Positive Perceptions of Student-Teacher Relationship}

High school science teacher's perceptions of a positive S-T relationship evolves when they have access to specific support such as teacher empowerment, teacher collaboration, time-out, and access to parents. Ali, et al. [15] suggested that building an S-T relationship has to be purposeful with continual effort on the part of the teacher. However, the findings of the research demonstrate that without the right kind of teacher support, S-T relationships are difficult to build. Responses from the participants in this research shows that teachers need to be empowered and provided time to invest in the building of these relationships. That is, participants' perceptions about S-T relationships have evolved over time spent in the field. Wessam stated that the student's behavioral commitment, which was enforced by the administration, empowered her and changed her perceptions about her students, "let's talk about the previous year when I taught science to grade 8; I [had] some problems with them. I had three sections, and I talked with the vice principal, and they talked with them about this problem. She said 'okay, we will solve this problem' and she talked directly with their parents. And the other [day], I see mashallah (what God has willed) all the students [were] active inside the class; because they directly talked, they found like solution for that." Furthermore, Rand cited her experience about how effective administration support can increase the moral of teachers in relating with students, "It was like the biggest support, and it was a common feeling between all the teachers in the school. So being a common feeling in the [teacher] community that the admin will support you, if you report the misbehavior [of students]. [They do this by] supporting [you] in front of the students even if later, [when you are] alone they will tell you what to do and what not to do"

Collaboration among teachers is another avenue for teacher's perception to evolve about a positive S-T relationship. Many of the discussions, teachers have during meetings centers on their students; teachers tend to share their field experiences with one another about how to better relate with a particular student in their classroom. Rand articulated this point, "So I would talk to the teacher who taught them in the previous grade, what behavior they had, asking the other teachers what happen to the student. This is the only social information: working with other teachers that taught the same student. I think it's really effective." In addition, Hamad suggested that when teachers and students have a "time-out" moment, it can also evolve their perception. Time-out refers to a break from purely academic activities: a time that fosters informal discussions between teachers and students, helping teachers and students get to know each other better. Hamad shared this perspective, "Field trips: let the teacher go out with the students, they will play together, they will go together to any picnic, or whatever, or the place where they'll get close to each other outside the school or outside the classroom. He has to realize that he has to build good relationships with them." Rand shared her opinion about "time-out" as well, "I just said teaching girls in high school, it (time-out) happens to help so much. For them to have someone and I'm not saying in the class, even during the school day they can come to you". However, Rand stressed that in trying to get to know the students out of class and build a positive S-T relationship, she is careful to set flexible boundaries

All of the participants asserted that being a parent and having direct access to the parent of their students can also help them build a positive S-T relationship. Most participants, five out of six, claim there is a communication gap between teachers and parents, and as described previously, many attributes this to administrators who do not trust teachers enough to converse 
with parents. This lack of trust, participants reported, restricts them from knowing more about their students. Hamad stated that, "When I became a parent, for example have kids, I believe[d] [in] it (S-T relationships) more because I put these students in the situation of my kids." Wessam added, "I talked with their parents. I asked them about their behavior inside [their] home and they said they have something, like, they have this personality; they hate this thing, like that. So, when I talked with them (students), I know the things that they hated... I talked with them in a way that they loved."

Building an S-T relationship should be purposeful; however, it requires quality time invested by teachers as well as the effective support from the administration. It is needful for teachers to utilize the non-classroom space and initiate informal discussion with their students in a quest to make students know them better and vice-versa. In summary, teacher empowerment, teacher collaboration, time-out, access to parent or being a parent increases the perception of teachers towards a strong and purposeful S-T relationship.

\subsection{Behavioral Model}

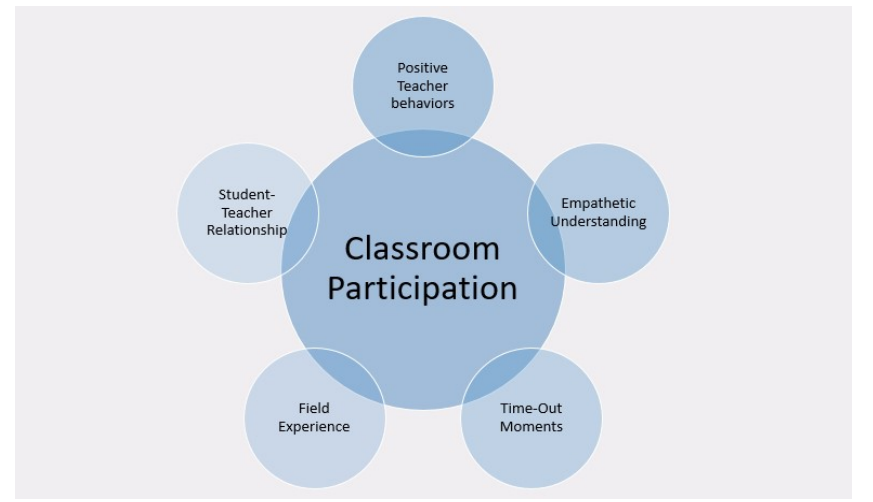

Figure 1: Summary of findings.

The central idea of this study explored the teacher's behaviors that influence student classroom participation. The model in Figure 1 represents the cyclical nature of these findings of this study in a more holistic fashion. Specifically, the ways in which the themes are related to one another are demonstrated above. Figure 1 demonstrates the intersectionality of how student classroom participation, represented in the center ring, relates to leadership skills: positive teacher behaviors, S-T relationships, empathetic understanding of teacher needs, and field experience.

Findings from this study shows that positive-teacherbehaviors, such as: assuming a parental role, giving students responsibility, using creativity, and possessing a sense of humor may influence student's classroom participate. Exhibiting such behaviors requires teachers to have a strong and purposeful relationship with their students, S-T relationship. Unfortunately, there are several barriers to establishing this critical facet of promoting student engagement. The findings from this study suggest that teachers may not receive the support needed to help facilitate positive $\mathrm{S}-\mathrm{T}$ relationships because administrators may not possess an empathetic understanding to teacher needs. Participants in this sample discussed, in great detail, the value of coaching as a means to professional growth; access to parents and guardians; and trust as significant support mechanism for teachers. They described the need for administrators to protect teachers from verbal abuse from both students and guardians. Finally, teachers must be willing to create purposeful, Time-Out Moments (TOM) with students. Positive teacher behaviors, implemented with effective support, in conjunction with TOMs, and length of teacher's field experience will help facilitate the perception of a positive S-T relationship. When the S-T relationship is in place, teachers will be more likely to exhibit the positive behaviors to promote student's classroom participation. This cycle then continues.

\section{DISCUSSION}

Findings of this study could offer a valuable contribution to the growing literature of S-T relationship in the Arab world as well as assist both administrators and educators in making decisions that will influence science student's classroom participation. It also demonstrates the need for school leaders to have an empathetic understanding of teachers need so as to facilitate student's classroom performance. Participant in this study showed that building an S-T relationship is paramount for teachers who want to engage students in their classroom. With years of experience, they were able to identify specific behaviors (Assuming parental role, giving student responsibilities, Creativity, and sense of humor) they believe teachers should be exhibited in the classroom to foster student's participation. It is worthy of note however that during the codes categorization, these four behaviors emerged as dominant codes (codes with the highest frequency and connected to the most participants), whereas "Assuming a parental role" had the highest frequency count. This might imply that this behavior matters most to the teachers in building an S-T relationship [36].

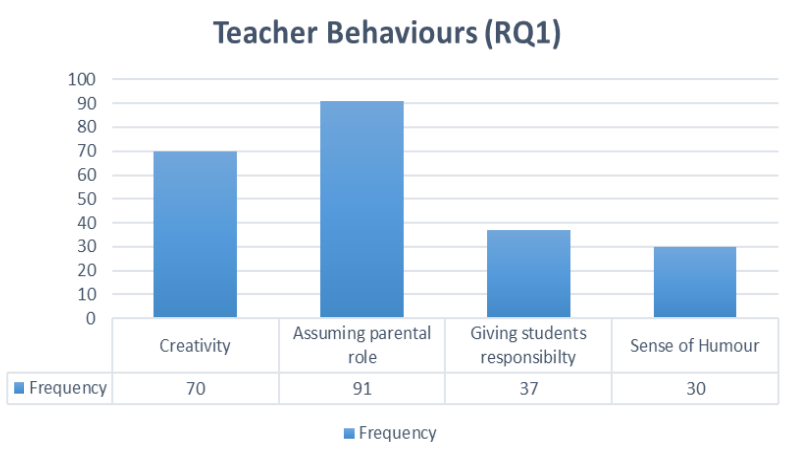

Figure 2: Chart showing Axial codes and frequency under 'TEACHER BEHAVIORS (RQ1)'.

All participants of the current study agreed that professional development training has vital process for the teaching profession [38]. However, they indicated a strong need for active teacher-coaching and teacher-mentoring, rather than passive, primarily rote, teacher training programs that are common in schools as the primary form of professional 
development. Some factors (e.g., budget) can sometimes limit how much administrators are willing to invest in teacher, but if the investment is seen as a future benefit to the organization, investment in teachers will not be an issue [39]. Participants in this study suggested that the professional development will be more beneficial if it is a blend of coaching and training. Administrators should initiate programs that is tailored to address the true needs of teachers. Induction programs for new teachers as well as feedback from existing teachers could be a starting point. Each program should include components that will address the individual needs and be a natural fit for teachers within a school system. Many students lose interest from science because of the teachers' lack of creativity in linking the topic to real-life as well as using experimental tools to demonstrate the concept. The school administrators should provide the necessary lab tools necessary for teachers to carry out experiment, nevertheless the teacher should be creative to find simulation tools via the internet which can be used in the class with students. Simply assuming a general need without careful consideration as to specific needs of the teachers within a school system will not provide a solution to the job dissatisfaction as expressed by teachers in current study. It is essential that administrators are empathetic to fully understand the pressing needs of teachers per time, and not just assume that they know.

Trust evolved as a specific support needed by all participants of this study, which unfortunately was absent in the administrator to teacher relationship. This lack of trust made the teachers feel insecure about their job, thereby leading to job dissatisfaction, which if not resolved could cause disengagement of teachers with a consequent lack of focus on professional activities and being negative in their job [40]. Administrators should listen actively to the teachers and not just parents about the disposition of students in the classroom, they should trust the teachers enough to carry out their job effectively. If teachers feel un-trusted with the responsibility given to them, they may feel incapacitated, and that can undermine their moral to want to exhibit the right behaviors in the classroom.

It is important to note, that there is a chronological relationship between teacher's field experience and evolving perceptions about a positive S-T relationship [41]. Field experience is critical to improving teacher's perception as to whether they can successfully carry out anticipated behaviors when engaging with students. The field experience tends to build their self-efficacy, given them the conviction that they can successfully execute the behavior required to produce desired outcomes [17]. Teachers' perception of an S-T relationship evolves overtime, and one of the ways to foster this perception is by having a "time-out" moment with students, this does not have to be in the classroom. It could be during break time, or during a field trip etc., teacher should cease the moment to initiate purposeful discussion that would lean towards building an S-T relationship. When students feel that teachers are concerned about their welfare generally, they tend to show interest in listening to the teacher more [6].
While this study points out the behaviors that influence student classroom participation and identifies how perceptions of an S-T relationship can evolve from the perspective of the teacher. More research needs to be conducted, in understanding student's perceptions of teacher's behaviors that motivates them. Future research should also consider triangulating reports from teacher participants with reports from their students to ensure that indeed there is an S-T relationship thereby making the data more reliable.

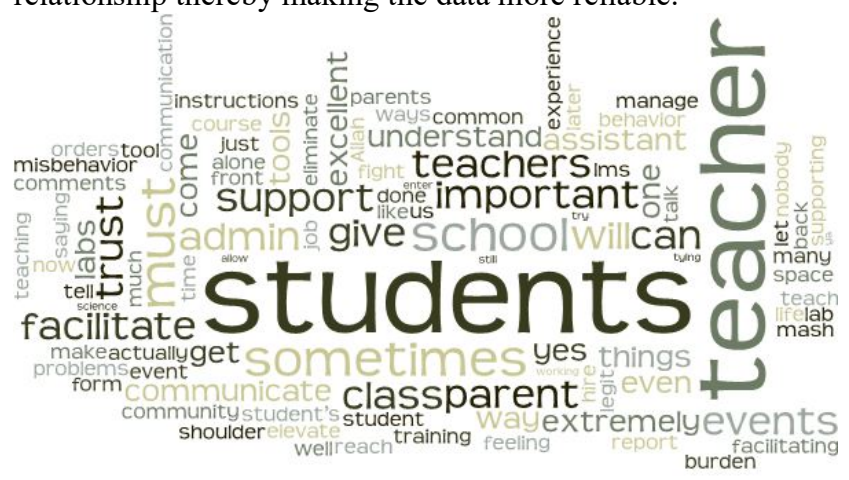

Figure 3: Word cloud based on Empirical Indicators under 'Evolving Perceptions' (RQ3).

\section{LIMITATIONS}

Discussing the limitations of this research methodology is crucial. First of all, the diversity of teacher's behavior that influences classroom participation of high school science students is limited due to the small number of participants in the study. Hence, the ability to generalize the findings of this study is limited [42]. Another limitation of this study is that the researchers position as an instrument of data collection might affect the objectivity of the data [43]. However, the sharing of observational data with the participants and the researcher practicing epoche had a positive effect on evaluating the reliability of the data [36]. Finally, all the six teachers who participated in the study were deemed to have a strong S-T relationship based on the criteria listed in the methodology section. This could be viewed as limiting the analysis from the perspective of some of their students who may not rate their S-T relationship favorably.

\section{REFERENCES}

[1] Crow, S. R., Knoell, C. M., Kracl, C., \& Harshbarger, D. (2015). Do you think like a fifth-grader? Exploring the teacher characteristics of importance to students from two diverse elementary schools in a rural Midwestern community. International journal of psychology: a biopsychosocial approach, 17, 39-56.

[2] Fraser, B. J., Aldridge, J. M., \& Soerjaningsih, W. (2010). Instructor-student interpersonal interaction and student outcomes at the university level in Indonesia. The Open Education Journal, 3(1).

[3] Goetz, T., Bieleke, M., Gogol, K., van Tartwijk, J., Mainhard, T., Lipnevich, A. A., \& Pekrun, R. (2021). Getting along and feeling good: Reciprocal associations between student-teacher relationship quality and students' emotions. Learning and Instruction, 71, 101349. 
[4] Maulana, R., Opdenakker, M. C., den Brok, P., \& Bosker, R. (2011). Teacher-student interpersonal relationships in Indonesia: profiles and importance to student motivation. Asia Pacific Journal of Education, 31(1), 33-49.

[5] Longobardi, C., Settanni, M., Lin, S., \& Fabris, M. A. (2021). Student-teacher relationship quality and prosocial behaviour: the mediating role of academic achievement and a positive attitude towards school. British Journal of Educational Psychology, 91(2), 547-562.

[6] Noddings, N. (1992). Noddings, Nel, The Challenge to Care in Schools: An Alternative Approach to Education. New York: Teachers College Press, 1992.

[7] Aschbacher, P. R., Li, E., \& Roth, E. J. (2010). Is science me? High school students' identities, participation and aspirations in science, engineering, and medicine. Journal of Research in Science Teaching: The Official Journal of the National Association for Research in Science Teaching, 47(5), 564-582.

[8] Maton, K., Martin, J. R., \& Doran, Y. J. (Eds.). (2021). Teaching Science: Knowledge, Language, Pedagogy. Routledge.

[9] Tosun, C., \& Öztürk, S. (2021). Science teachers and preservice science teachers' science teaching competence belief scores in the resource room in terms of certain variables. Teachers and Teaching, 1-30.

[10] Skinner, B. F. (1967, December). Teaching science in high School-What is wrong. In meeting of the American Association for the Advancement of Science, 29.

[11] Guedenon, P., Dehoumon, B. A., \& da Conceiçao, Y. S. (2014). Contribution to the Improvement of Class Teaching of Life and Earth Sciences through the Use of Audio-Visual Materials at Pylone High School (Benin). European Journal of Contemporary Education, 9(3), 140-148.

[12] Jarlath, O. (2021). Better Behaviour: A Guide for Teachers. Sage.

[13] Leekitchwatana, P., \& Pimdee, P. (2021). An Analysis of Thai Student Teacher Appropriate Internet Use Behaviour. International Journal of Emerging Technologies in Learning (IJET), 16(2), 254-271.

[14] Ulug, M., Ozden, M. S., \& Eryilmaz, A. (2011). The effects of teachers' attitudes on students' personality and performance. Procedia-Social and Behavioral Sciences, 30, 738-742.

[15] Ali, A., Khan, D. M., \& Hussain, M. (2018). Causes of teacher's favoritism and its effects on the university students: A case study. Global Social Sciences Review, 3(2), 369-384.

[16] Sutherland, K. S., \& Morgan, P. L. (2003). Implications of transactional processes in classrooms for students with emotional/behavioral disorders. Preventing school failure: alternative education for children and youth, 48(1), 32-37.

[17] Bandura, A. (1977). Self-efficacy: toward a unifying theory of behavioral change. Psychological review, 84(2), 191.

[18] Fackler, S., Malmberg, L. E., \& Sammons, P. (2021). An international perspective on teacher self-efficacy: personal, structural and environmental factors. Teaching and Teacher Education, 99, 103255.

[19] Locke, E. A. (1997). Self-efficacy: The exercise of control. Personnel psychology, 50(3), 801.

[20] Myyry, L., Karaharju-Suvanto, T., Virtala, A. M. K., R Raekallio, M., Salminen, O., Vesalainen, M., \& Nevgi, A.
(2021). How self-efficacy beliefs are related to assessment practices: a study of experienced university teachers. Assessment \& Evaluation in Higher Education, 1-14.

[21] Carr, E. G., Taylor, J. C., \& Robinson, S. (1991). The effects of severe behavior problems in children on the teaching behavior of adults. Journal of Applied Behavior Analysis, 24(3), 523535 .

[22] Harris, M. J., Rosenthal, R., \& Snodgrass, S. E. (1986). The effects of teacher expectations, gender, and behavior on pupil academic performance and self-concept. The Journal of Educational Research, 79(3), 173-179.

[23] Bojanek, E. K., Raley, S. K., Shogren, K. A., \& Lane, K. L. (2021). Examining the impact of professional development on the Self-determined learning model of instruction for general and special educators. Inclusion, 9(2), 118-133.

[24] Kwok, A., Keese, J., Suárez, M. I., Mitchell, D., \& Huston, D. (2021). Novice teacher vertical professional development? Exploring teachers' and coaches' beliefs throughout a two-year induction program. Learning Environments Research, 1-16.

[25] Sancar, R., Atal, D., \& Deryakulu, D. (2021). A new framework for teachers' professional development. Teaching and Teacher Education, 101, 103305.

[26] Education in the United Arab Emirates (2018).

[27] Al-Naqbi, F., \& Mustaffa, W. S. W. (2021). Developing a Model for Smart Learning in Secondary Education in the UAE. International Journal of Management (IJM), 12(1).

[28] Minton, M., \& Bligh, B. (2021). Examining the use of Kahoot to support digital game-based formative assessments in UAE higher education. Studies in Technology Enhanced Learning, 1(2), 445-462.

[29] Denzin, N. K., \& Lincoln, Y. S. (2005). The Discipline and Practice of Qualitative Research Introduction. The landscape of qualitative research, 1-43.

[30] Creswell, J. W., \& Poth, C. N. (2016). Qualitative inquiry and research design: Choosing among five approaches. Sage publications.

[31] Creswell, J. W., \& Creswell, J. D. (2017). Research design: Qualitative, quantitative, and mixed methods approaches. Sage publications.

[32] Robson, C. (2002). Real world research: A resource for social scientists and practitioner-researchers. Wiley-Blackwell.

[33] Yin, R. K. (2009). Case study research: design and methods/Robert K. Yin, Applied social research methods series, 5 .

[34] Kelly, B. T., Stage, F. K., \& Manning, K. (2003). Research in the college context: Approaches and methods.

[35] Dowling, P., \& Brown, A. (2012). Doing research/reading research: Re-interrogating education. Routledge.

[36] Adu, P. (2019). A step-by-step guide to qualitative data coding. Routledge.

[37] Birks, M., \& Mills, J. (2015). Grounded theory: A practical guide. Sage.

[38] Collinson, V., Kozina, E., Kate Lin, Y. H., Ling, L., Matheson, I., Newcombe, L., \& Zogla, I. (2009). Professional development for teachers: A world of change. European journal of teacher education, 32(1), 3-19.

[39] Levine, M. (2002). Why Invest in Professional Development Schools? Educational Leadership, 59(6), 65-68. 
[40] Okeke, C. I., \& Mtyuda, P. N. (2017). Teacher Job Dissatisfaction: Implications for Teacher Sustainability and Social Transformation. Journal of Teacher Education for Sustainability, 19(1), 57-68.

[41] Caprano, R. M., Capraro, M. M., Capraro, R. M., \& Helfeldt, J. (2010). Do differing types of field experiences make a difference in teacher candidates' perceived level of competence? Teacher Education Quarterly, 37(1), 131-154.

[42] Mears, C. L. (2009). Interviewing for education and social science research: The gateway approach. Springer.
[43] Gillham, B. (2000). Case study research methods. Bloomsbury Publishing.

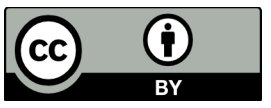

(C) 2021 by the Olatunji Jacob Ajayi and Alexandria A. Proff. Submitted for possible open access publication under the terms and conditions of the Creative Commons Attribution (CC BY) license (http://creativecommons.org/licenses/by/4.0/). 